\title{
The water deprivation test and a potential role for the arginine vasopressin precursor copeptin to differentiate diabetes insipidus from primary polydipsia
}

\author{
M de Fost ${ }^{1}$, S M Oussaada ${ }^{1}$, E Endert' ${ }^{2}$, G E Linthorst ${ }^{1}$, M J Serlie ${ }^{1}$, M R Soeters ${ }^{1}$, \\ J H DeVries' ${ }^{1}$, P H Bisschop' ${ }^{1}$ and E Fliers ${ }^{1}$
}

${ }^{1}$ Department of Endocrinology and Metabolism, Room F5-164, and 2Laboratory of Endocrinology, Department of Clinical Chemistry, Academic Medical Center, University of Amsterdam, Meibergdreef 9, 1105 AZ Amsterdam, The Netherlands
Correspondence should be addressed to $\mathrm{M}$ de Fost

Email

m.defost@amc.uva.nl

\begin{abstract}
The water deprivation test is the gold standard test to differentiate central or nephrogenic diabetes insipidus (DI) from primary polydipsia (PP) in patients with polyuria and polydipsia. Few studies have addressed the diagnostic performance of this test. The aim of this retrospective cohort study was to evaluate the diagnostic performance of the standard water deprivation test, including plasma arginine vasopressin (AVP) measurements, in 40 consecutive patients with polyuria. We compared initial test results with the final clinical diagnosis, i.e., no DI, central DI, or nephrogenic DI. The median length of follow-up was 8 years. In a subset of ten patients, the novel marker copeptin (CP) was measured in plasma. Using the final diagnosis as a gold standard, a threshold for urine osmolality of $>800 \mathrm{mOsmol} / \mathrm{kg}$ after water deprivation yielded a sensitivity and specificity of 96 and $100 \%$, respectively, for diagnosing PP. Sensitivity increased to $100 \%$ if the cut-off value for urine osmolality was set at $680 \mathrm{mOsmol} / \mathrm{kg}$. Plasma AVP levels did not differ between patient groups and did not differentiate among central DI, nephrogenic DI, or PP. In all three patients with central DI, plasma CP was $<2.5 \mathrm{pmol} / \mathrm{l}$ with plasma osmolality $>290 \mathrm{mOsmol} / \mathrm{kg}$, and $>2.5 \mathrm{pmol} / \mathrm{l}$ in patients without DI. The optimal cut-off value for differentiating PP from DI during a water deprivation test was urine osmolality $>680 \mathrm{mOsmol} / \mathrm{kg}$. Differentiating between central and nephrogenic DI should be based on clinical judgment as AVP levels did not discriminate.
\end{abstract}
Key Words
copeptin
- diabetes insipidus
- pituitary
- polydipsia
- polyuria
- primary polydipsia
- arginine vasopressin
- water deprivation test
- psychogenic polydipsia

Endocrine Connections (2015) 4, 86-91

\section{Introduction}

Polyuria (diuresis $>31$ /day) in the absence of common causes, such as hypercalcemia, hyperglycemia, or relief of urinary tract obstruction, can be caused by diabetes insipidus (DI) or primary polydipsia (PP, also referred to as psychogenic polydipsia). DI can be divided in central
DI, caused by impaired secretion of the antidiuretic hormone arginine vasopressin (AVP) from the posterior pituitary and nephrogenic DI, which is due to decreased sensitivity of the kidney to AVP. In DI, the primary defect is polyuria, leading to a compensatory polydipsia.

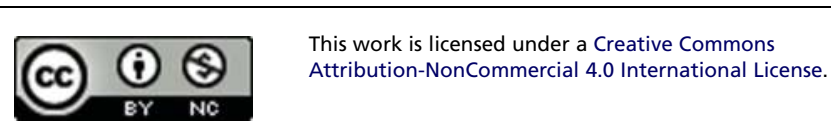


In contrast, the primary defect in PP is excessive water intake often associated with behavioral abnormalities.

DI and PP can be differentiated by performing a water deprivation test (1). In healthy subjects, water deprivation causes the plasma osmolality to rise above 280$290 \mathrm{mOsmol} / \mathrm{kg}$, which leads to the release of AVP into the circulation. In the collecting ducts of the kidney, AVP binds to the vasopressin type 2 receptor and this is followed by expression of aquaporin 2 channels. This results in increased water retention with a rise in urine osmolality to a maximum of 1000-1200 mOsmol/ $\mathrm{kg}$ and restoration of plasma osmolality toward the reference range (2). In DI, polyuria continues despite water deprivation, with dilution of urine in the presence of high plasma osmolality. Traditionally, the plasma AVP concentration is then used to differentiate central from nephrogenic DI. Plasma AVP should be inappropriately low in central DI and elevated in nephrogenic DI, reflecting inappropriate AVP action. In addition, the administration of the AVP analog desmopressin acetate at the end of the test may help to differentiate central from nephrogenic DI, as the antidiuretic response is theoretically preserved in central DI, but not in nephrogenic DI.

The diagnostic value of the water deprivation test has not been studied extensively. A recent review identified only 15 publications on the differential diagnosis of DI (3). These papers reported on mainly small series, used different protocols, and focused only on one part of the differential diagnostic spectrum of DI. In addition, data on the diagnostic value of AVP determination were inconsistent, probably due to its pre-analytical and analytical difficulties including a short half-life and pre-analytical instability $(4,5)$.

Recently, the AVP precursor copeptin (CP), which is co-secreted with AVP from the posterior pituitary, has been suggested to hold promise as a diagnostic tool in the differential diagnosis of DI, but only limited data are available $(6,7)$.

The aim of this study was to evaluate the diagnostic performance of the standard water deprivation test, including plasma AVP measurement, in a series of consecutive patients with polyuria in our hospital. In a small subset of cases, we explored whether CP is useful in differentiating among PP, nephrogenic, and central DI.

\section{Materials and methods}

\section{Study population}

All adult patients who underwent a water deprivation test at the Academic Medical Centre (AMC) of the University of Amsterdam between 1994 and 2011 were included. Hypercalcemia and hyperglycemia were excluded in all subjects. None of the subjects used desmopressin (DDAVP) or drugs that may interfere with the results of the water deprivation test $(8,9)$. Our gold standard was the final (or - if applicable - final pre-mortem) clinical diagnosis, which was determined from patient files or by contacting the patients or their treating physician (internists or general practitioner). Patients were categorized as having a clinical diagnosis of no DI, central DI, or nephrogenic DI, based on whether or not they suffered from polyuria or used desmopressin.

\section{Water deprivation test}

Patients were admitted to our ward in the evening before the test day, and fluid intake was stopped at $0700 \mathrm{~h}$. Access to water was prevented by shutting down water pipes and by removing all objects containing water, such as vases. Every hour, patients were weighed and urine and blood samples were collected for the determination of plasma and urine sodium, potassium, and osmolality and of plasma AVP.

There was no pre-set maximum length of water deprivation. Water deprivation was discontinued when one of the following criteria was met: i) an urine osmolality of at least $800 \mathrm{mOsmol} / \mathrm{kg}$. This was considered to be diagnostic of PP and ii) a weight loss of more than 5\% from baseline or a plasma osmolality exceeding $300 \mathrm{mOsmol} / \mathrm{kg}$. This was considered to be diagnostic of DI. Subsequently, if patients were known to have a pituitary disorder, a diagnosis of central DI was made. If the subject used lithium, then diagnosis of nephrogenic DI was made. If the subject neither had pituitary disease nor used lithium, we differentiated between central DI and nephrogenic DI according to the normogram for plasma AVP vs plasma osmolality or urine osmolality according to Robertson (10). In eight patients who met criterion 2 , desmopressin (DDAVP) $2 \mu \mathrm{g}$ i.v. was given and urine osmolality was measured after $1 \mathrm{~h}$. From ten patients, frozen plasma samples were available to determine $\mathrm{CP}$.

\section{Laboratory analysis}

Until 2005, AVP was measured with an in-house developed RIA after solid-phase extraction and standard addition to each sample. The detection limit was $0.1 \mathrm{pmol} / 1$ with an inter-assay variation of $8.5 \%$ at 2 pmol/l. From 2006 onwards, AVP was measured using a commercial RIA (Euria-Vasopressin, Euro-Diagnostica AB,

This work is licensed under a Creative Commons Attribution-NonCommercial 4.0 International License. 
Table 1 Descriptives and outcomes of the water deprivation test of the study population, given as median (range).

\begin{tabular}{l}
\hline$n$ \\
Age (years) \\
Nadir urinary osmolality (mOsmol/kg) \\
Peak urinary osmolality (mOsmol/kg) \\
Nadir plasma osmolality (mOsmol/kg) \\
Peak plasma osmolality (mOsmol/kg) \\
Weight loss (\%) \\
Minimum diuresis/h (ml) \\
Maximum diuresis/h (ml) \\
Duration of water deprivation (h) \\
AVP (pmol/l) \\
CP (pmol/l)
\end{tabular}

\begin{tabular}{c}
\hline No DI \\
\hline 27 \\
$33(19-68)$ \\
$449(64-960)$ \\
$819(680-960)$ \\
$286(273-297)$ \\
$292(276-305)$ \\
$0.7(0-4.1)$ \\
$21(0-300)$ \\
$103(18-800)$ \\
$10(1-29)$ \\
$0.8(0.1-4.0)$ \\
$7.0(2.0-8.8)$ \\
\hline
\end{tabular}

\begin{tabular}{c}
\hline Central DI \\
\hline 12 \\
$46(24-74)$ \\
$149(56-385)$ \\
$342(67-559)$ \\
$290(260-298)$ \\
$302(296-306)$ \\
$2.6(0.8-5.4)$ \\
$100(0-250)$ \\
$250(130-600)$ \\
$7(1-18)$ \\
$0.5(0.1-4.3)$ \\
$2.2(1.9-2.5)$
\end{tabular}

\begin{tabular}{c} 
Nephrogenic DI \\
\hline 1 \\
51 \\
196 \\
203 \\
293 \\
314 \\
\\
\\
11 \\
\end{tabular}

$P$ value no DI vs central DI

DI, diabetes insipidus; AVP, arginine vasopressin; CP, copeptin

Malmö, Sweden), which contains the same antibody as the in-house assay. The detection limit was $0.5 \mathrm{pmol} / 1$ and the inter-assay variation $11.5 \%$ at $2.5 \mathrm{pmol} / \mathrm{l}$. CP was measured by an immunoluminometric assay (BRAHMS CT-proAVP LIA, BRAHMS GmbH, Thermo Scientific, Henningsdorf, Germany). The detection limit was $0.4 \mathrm{pmol} / \mathrm{l}$ and inter-assay variation $12.4 \%$ at $4 \mathrm{pmol} / \mathrm{l}$. Osmolality was measured on OSMOstation OM-6050 (Arkray, Kyoto, Japan).

\section{Statistical analysis}

Data were analyzed using the SPSS Software (IBM, version 20). Results are expressed as median and range. Differences between patient groups were assessed using the MannWhitney $U$ test. A $P$ value $<0.05$ was considered statistically significant.

\section{Results}

\section{Patients}

A total of 70 water deprivation tests were performed between 1994 and 2011. Sixteen tests were stopped for unknown reasons while formal stopping criteria were not. Four could not be evaluated because of missing data. Ten patients were lost to follow-up. This resulted in 40 water deprivation tests in 12 men and 28 women who had undergone a complete standard water deprivation test and for whom a final clinical diagnosis was established (no DI, central DI, or nephrogenic DI) (Table 1). The median length of follow-up was 8 years (range $2-18$ years).

Out of 40 patients, 15 had pituitary disease $(n=1$ sarcoidosis, $n=1$ Langerhans cell histiocytosis, $n=1$ Rathke's cleft cyst, $n=7$ transsphenoidal resection of a sellar tumor (either with or without radiotherapy), $n=4$ pituitary insufficiency after radiotherapy for a cerebral tumor, and $n=1$ Sheehan syndrome). Two patients had polyuria after a head trauma. One patient had polyuria while using lithium. The remaining 22 patients had unexplained polyuria.

\section{Final clinical diagnosis}

The final clinical diagnosis was no DI in 27 patients, central DI in 12 patients, and nephrogenic DI in one patient. The patient with nephrogenic DI used lithium. Of the patients with central DI, seven had pituitary disease, one had suffered a head trauma, and four were diagnosed according to the normogram. All patients with DI still used desmopressin or had used desmopressin until they died.

In all but two patients, the final clinical diagnosis was identical to the original diagnosis based on the water deprivation test. The two exceptions were patient no. 1, who developed polyuria after a head trauma. After $16 \mathrm{~h}$ of water deprivation, the test was terminated because of a plasma osmolality of $306 \mathrm{mOsmol} / \mathrm{kg}$ and

Table 2 Two-by-two table based on the current cut-off value for urine osmolality ( $>800 \mathrm{mOsmol} / \mathrm{kg}$ ).

\begin{tabular}{|c|c|c|c|}
\hline & \multicolumn{3}{|c|}{ Final clinical diagnosis } \\
\hline & DI & No DI & Total \\
\hline \multicolumn{4}{|l|}{ First criterion reached } \\
\hline $\begin{array}{l}\text { Maximum urine osmolality } \\
>800 \mathrm{mOsmol} / \mathrm{kg}\end{array}$ & 0 & 26 & 26 \\
\hline $\begin{array}{l}\text { Plasma osmolality }>300 \mathrm{mOsmol} / \mathrm{kg} \\
\text { or weight loss }>5 \%\end{array}$ & 13 & 1 & 14 \\
\hline Total & 13 & 27 & 40 \\
\hline
\end{tabular}

DI, diabetes insipidus 
Table 3 Two-by-two table based on a cut-off value for urine osmolality of $>680 \mathrm{mOsmol} / \mathrm{kg}$.

\begin{tabular}{|c|c|c|c|}
\hline & \multicolumn{3}{|c|}{ Clinical diagnosis } \\
\hline & DI & No DI & Total \\
\hline \multicolumn{4}{|l|}{ First criterion reached } \\
\hline $\begin{array}{l}\text { Maximum urine osmolality } \\
>680 \mathrm{mOsmol} / \mathrm{kg}\end{array}$ & 0 & 27 & 27 \\
\hline $\begin{array}{l}\text { Plasma osmolality }>300 \mathrm{mOsmol} / \mathrm{kg} \\
\text { or weight loss }>5 \%\end{array}$ & 13 & 0 & 13 \\
\hline Total & 13 & 27 & 40 \\
\hline
\end{tabular}

DI, diabetes insipidus.

a urine osmolality of $480 \mathrm{mOsmol} / \mathrm{kg}$. The patient subsequently used desmopressin for several months. After cessation of desmopressin; however, polyuria did not recur. Temporary DI is a well-known complication of severe head trauma (11). Therefore, we consider this patient to have had a temporary central DI. Patient no. 2 suffered from Wegener's disease and concomitant polyuria. She had no pituitary, neurological disease or head trauma. After $22 \mathrm{~h}$ of water deprivation, she had a plasma osmolality of $301 \mathrm{mOsmol} / \mathrm{kg}$ and a urine osmolality of $680 \mathrm{mOsmol} / \mathrm{kg}$. At this point, her diuresis had decreased to $0 \mathrm{ml} / \mathrm{h}$. Based on the test criteria, the diagnosis was DI. However, the anuria during water deprivation made us conclude that she did not suffer from DI. As anticipated, the polyuria disappeared spontaneously within a year after the test. She had not used desmopressin at any time.

\section{Test criteria}

Test parameters of both patient groups are given in Table 1 . In 26 patients, the first criterion that was reached was a urine osmolality $>800 \mathrm{mOsmol} / \mathrm{kg}$ (after a median of $10 \mathrm{~h}$, range $1-29 \mathrm{~h}$ ), indicative of PP. All these patients have a final clinical diagnosis of PP (sensitivity 96\%, specificity $100 \%$, Tables 2 and 3). One of the patients who did not reach a urine osmolality of $800 \mathrm{mOsm} / \mathrm{kg}$ had a final clinical diagnosis of PP (patient no. 2). The remaining 14 patients continued the water deprivation until the plasma osmolality exceeded $300 \mathrm{mOsmol} / \mathrm{kg}$ (12 patients) or weight loss exceeded 5\% (two patients). Seven of these patients, all with a final clinical diagnosis of central DI, received desmopressin at the end of the test with a median rise in urine osmolality of $75 \mathrm{mOsmol} / \mathrm{kg}$ (range 41-248 mOsmol $/ \mathrm{kg}$ ).

The median duration of water deprivation was $7 \mathrm{~h}$ (range 1-18 h). Sensitivity and specificity for DI or PP

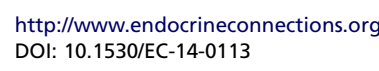

increased to $100 \%$ and $100 \%$ if the cut-off value for urine osmolality was set at $680 \mathrm{mOsmol} / \mathrm{kg}$.

\section{AVP and CP}

Plasma AVP levels at the time of discontinuation of the test showed considerable overlap between patient groups (no DI: 0.8 pmol/1 (0.1-4.0 pmol/1), central DI: 0.5 pmol/1 $(0.1-4.3 \mathrm{pmol} / \mathrm{l})(P=0.5)$, nephrogenic DI $11.0 \mathrm{pmol} / \mathrm{l})$ (Fig. 1).

As shown in Fig. 1, plasma CP from the ten patients at discontinuation of the test was significantly lower in patients with DI compared with those without DI (central DI $2.2 \mathrm{pmol} / \mathrm{l}(1.9-2.5 \mathrm{pmol} / \mathrm{l})$ vs no DI $7.0 \mathrm{pmol} / 1$ (2.0-8.8 pmol/1); median (range), $P=0.005$ ). When taking into account only samples with a plasma osmolality $>290 \mathrm{mOsmol} / \mathrm{kg}$, CP levels in patients with central DI
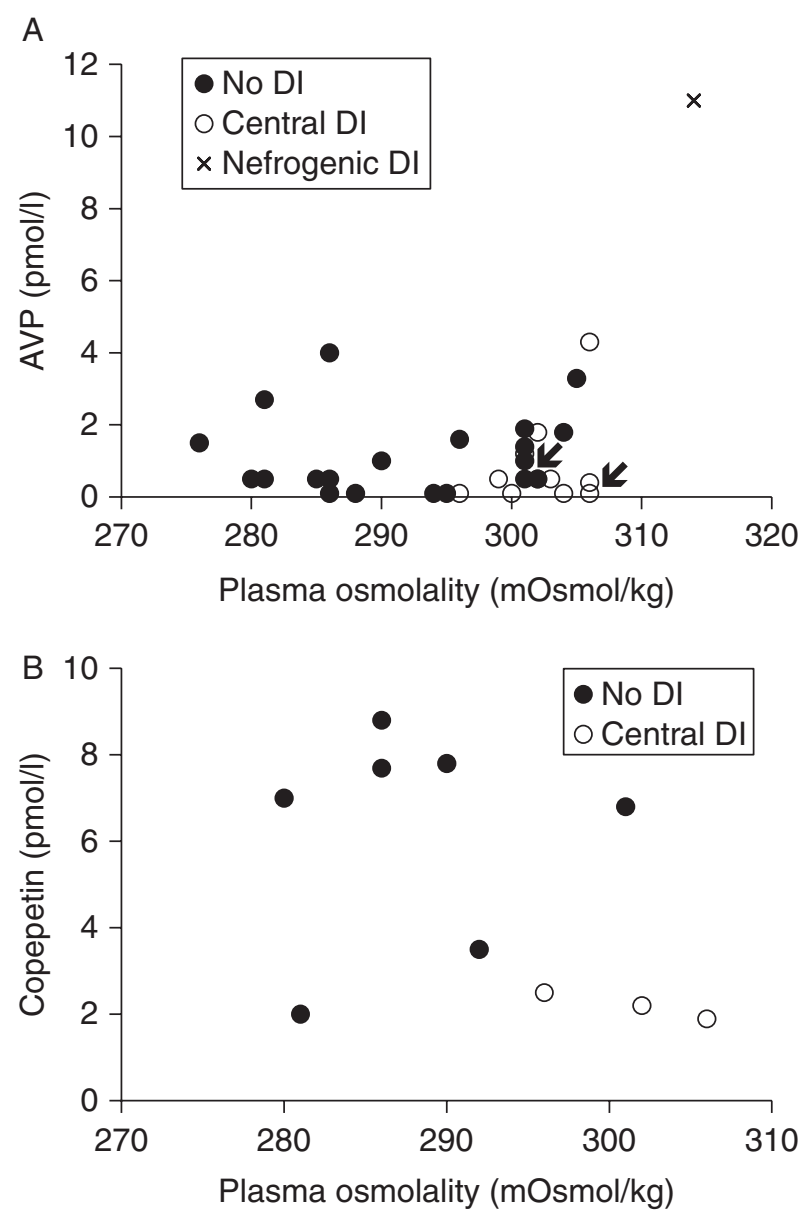

Figure 1

Plasma osmolality vs AVP (A) and CP (B) at the end of the water deprivation test. Arrows depict patient 1 (in the central DI group) and patient 2 (in the no DI group). DI, diabetes insipidus; $C P$, copeptin.

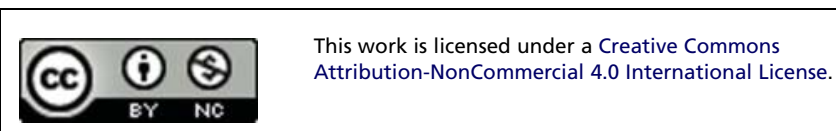



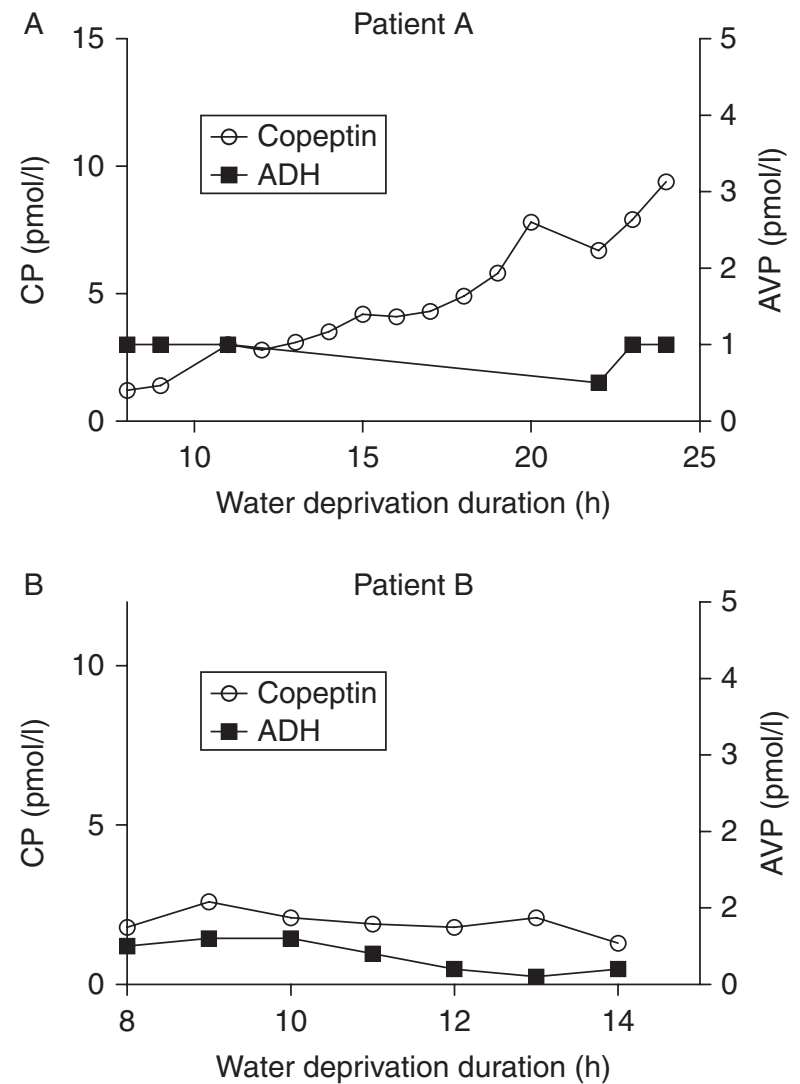

Figure 2

AVP and CP during water deprivation in a subject with PP $(A)$ and a subject with central DI (B). DI, diabetes insipidus; AVP, arginine vasopressin; $\mathrm{CP}$, copeptin.

were $<2.5 \mathrm{pmol} / \mathrm{l}$, but none was in the group without DI $(P<0.0001)$.

In two patients, hourly $\mathrm{CP}$ and AVP data were available (Fig. 2). Patient A did not have DI, and CP levels clearly increased during the test, while AVP levels remained low (Fig. 2). In patient B, who had central DI, both AVP and CP plasma levels remained low (Fig. 2).

\section{Discussion}

In this study, we evaluated the diagnostic performance of the water deprivation test as adapted from Miller et al. (1) in a series of consecutive patients to differentiate among PP, central, and nephrogenic DI. We also report on the novel marker CP in a small subset of patients.

In our series, the best parameter for diagnosing PP was a urine osmolality of $>680 \mathrm{mOsmol} / \mathrm{kg}$ after water deprivation (sensitivity and specificity 100\%). The original cut-off value of $800 \mathrm{mOsmol} / \mathrm{kg}$ resulted in a lower accuracy, misdiagnosing one patient as having DI.
Patients who did not achieve a urine osmolality of $>680 \mathrm{mOsmol} / \mathrm{kg}$, but instead reached a plasma osmolality $>300 \mathrm{mOsmol} / \mathrm{kg}$ or experienced weight loss of $>5 \%$, all had DI.

AVP levels did not differ between the patient groups. $\mathrm{CP}$ seemed to be a more promising marker. In our limited dataset for $\mathrm{CP}$, all patients with central DI had a CP level below $2.5 \mathrm{pmol} / \mathrm{l}$ at supranormal osmolality (>290 mOsmol/kg).

Importantly, we found that plasma AVP is not useful in the establishment of a final diagnosis. This may be due, at least in part, to methodological issues measuring plasma AVP. First, there is marked pre-analytical instability (5). In our study, AVP was collected in EDTA tubes with $500 \mathrm{kIU}$ aprotinin $/ \mathrm{ml}$ blood, and kept at $0-4{ }^{\circ} \mathrm{C}$ during transport and centrifugation. Samples were stored at $-20^{\circ} \mathrm{C}$ for a maximum of 2 months until assay. Therefore, it is unlikely that proteolytic degradation is responsible for the low values of AVP. By extracting AVP with a solid phase, some loss may occur, hence, in both RIAs, recovery was measured and corrected for. Furthermore, antibody heterogeneity between different immunoassays can give variable results. However, both assays in this study used the same antibody and this antibody has no crossreactivity with oxytocin (12). Therefore, we cannot explain the poor diagnostic performance of plasma AVP in our series.

Recently, CP has been proposed as a surrogate for AVP. $\mathrm{CP}$ is the C-terminal part of the AVP precursor that is co-secreted with AVP from the neurohypophysis. CP has a high in vitro stability and is relatively easy to measure (7). In a recent study, CP levels before start of water deprivation could be used to identify patients with complete central or nephrogenic DI (6). Unfortunately, our patient set in whom plasma CP levels were measured was small, but the preliminary results do hold promise in this respect.

There were several differences between our study and earlier studies. First, many authors have used hypertonic saline infusion instead of water deprivation to raise plasma osmolality (3). Others, such as the recent study by Fenske et al. (6) used water deprivation, but for a fixed period of $16 \mathrm{~h}$ during which only a limited number of samples were taken. The length of fluid restriction in our protocol depends on weight loss, and plasma- and urine osmolality, which is measured every hour. This makes our test more labor intensive and implies that for some subjects, particularly those with $\mathrm{PP}$, the duration of the test is longer. However, for subjects with DI, who are at a serious risk for dehydration, the test can be terminated earlier.

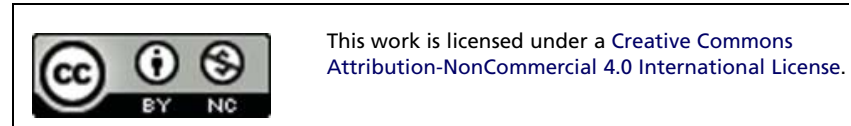


Another difference is that most studies used the relationship between plasma and urine osmolality as well as the relative increase in urine osmolality to differentiate DI from PP. We used absolute cut-off values for plasma and urine osmolality, which gave an excellent accuracy. Finally, our gold standard was the current clinical diagnosis of the patient. We feel that in the absence of a validated gold standard for diagnosing DI, this is the most appropriate approach.

One of the limitations of our study is that we did not systematically evaluate the response to desmopressin. Furthermore, a relatively large number of tests could not be used because of missing data or a loss to follow-up. In addition, we made no differentiation between complete and partial DI, thus potentially missing some of the mild cases of DI. The partial forms of DI are especially difficult to distinguish from chronic PP for several reasons. First, in patients with chronic PP aquaporin 2 channels in the kidney are down-regulated and there is washout of the renal medullary concentration gradient, resulting in inappropriately dilute urine and a poor response to exogenous AVP (13). This situation mimics DI. Secondly, patients with partial forms of DI may be able to concentrate urine to levels above plasma osmolality during dehydration $(10,14)$.

Based on our study, we conclude that the best parameter for differentiating PP from DI is urine osmolality, which is diagnostic for PP when exceeding $680 \mathrm{mOsmol} / \mathrm{kg}$ after prolonged water deprivation. Our data show that plasma AVP does not help to make this distinction. As suggested by others, we found that plasma $\mathrm{CP}$ holds promise in this respect. However, its role should be studied more extensively in larger groups and in a prospective manner.

\section{Declaration of interest}

The authors declare that there is no conflict of interest that could be perceived as prejudicing the impartiality of the research reported.

\section{Funding}

This research did not receive any specific grant from any funding agency in the public, commercial or not-for-profit sector.

\section{Acknowledgements}

The authors thank Martine van Vessem for her skilled assistance during the water deprivation test.

\section{References}

1 Miller M, Dalakos T, Moses A, Fellerman H \& Streeten D. Recognition of partial defects in antidiuretic hormone secretion. Annals of Internal Medicine 197073 721-729. (doi:10.7326/0003-4819-73-5-721)

2 Robertson G, Shelton R \& Athar S. The osmoregulation of vasopressin. Kidney International 197610 25-37. (doi:10.1038/ki.1976.76)

3 Fenske W \& Allolio B. Clinical review: Current state and future perspectives in the diagnosis of diabetes insipidus: a clinical review. Journal of Clinical Endocrinology and Metabolism 201297 3426-3437. (doi:10.1210/jc.2012-1981)

4 Czackzes J, Kleeman C \& Koening M. Physiologic studies of antidiuretic hormone by its direct measurement in human plasma. Journal of Clinical Investigation 196443 1624-1640.

5 Robertson G, Mahr E, Athar S \& Sinha T. Development and clinical application of a new method for the radioimmunoassay of arginine vasopressin in human plasma. Journal of Clinical Investigation 197352 2340-2352. (doi:10.1172/JCI107423)

6 Fenske W, Quinkler M, Lorenzo D, Zopf K, Haagen U, Papassotiriou J, Pfeiffer AF, Fassnacht M, Störk S \& Allolio B. Copeptin in the differential diagnosis of the polydipsia-polyuria syndrome - revisiting the direct and indirect water deprivation tests. Journal of Clinical Endocrinology and Metabolism 201196 1506-1515. (doi:10.1210/jc.2010-2345)

7 Morgenthaler N, Struck J, Alonso C \& Bergmann A. Assay for the measurement of copeptin, a stable peptide derived from the precursor of vasopressin. Clinical Chemistry 200652 112-119. (doi:10.1373/ clinchem.2005.060038)

8 Naves L, Vilar L, Costa A, Domingues L \& Casulari L. Distúrbios na secreção e ação do hormônio antidiurético. Arquivos Brasileiros de Endocrinologia e Metabologia 200347 467-481. (doi:10.1590/S000427302003000400019)

9 Oliveira S, Vilar L, Cavalcanti N, Castelar E, Moura E \& Leal E. Manuseio da síndrome da secreção inapropriada do ADH. In Endocrinologia Clinica, 2nd edn, pp 124-134. Eds L Vilar, E Castellar, E Moura, E Leal, AC Machado, L Teixeira, et al. Rio de Janeiro, Brazil: Medsi, 2001.

10 Robertson G. Diabetes insipidus. Endocrinology and Metabolism Clinics of North America 199524 549-572.

11 Agha A, Sherlock M, Phillips J, Tormey W \& Thompson C. The natural history of post-traumatic neurohypophysial dysfunction. European Journal of Endocrinology 2005 152 371-377. (doi:10.1530/eje.1. 01861)

12 Vasopressin EURIA Euro Diagnostica, available from: http://www. eurodiagnostica.com/index.php?headId=3\&pageId=3\&productId=58

13 Li C, Wang W, Kwon T, Isikay L, Wen J, Marples D, Djurhuus JC, Stockwell A, Knepper MA, Nielsen S \& Frøkiaer J. Downregulation of $\mathrm{AQP} 1,-2$, and -3 after ureteral obstruction is associated with a longterm urine-concentrating defect. American Journal of Physiology. Renal Physiology 2001281 163-171.

14 Baylis P \& Cheetham T. Diabetes insipidus. Archives of Disease in Childhood 199879 84-89. (doi:10.1136/adc.79.1.84)

Received in final form 19 February 2015

Accepted 23 February 2015 http://www.endocrineconnections.org

DOI: 10.1530/EC-14-0113
(C) 2015 The authors Published by Bioscientifica Lto
This work is licensed under a Creative Commons Attribution-NonCommercial 4.0 International License. 